NASA Technical Memorandum 103146

AIAA-90-2120

\title{
Cooling of Rocket Thrust Chambers With Liquid Oxygen
}

Elizabeth S. Armstrong and Julie A. Schlumberger Lewis Research Center

Cleveland, Ohio

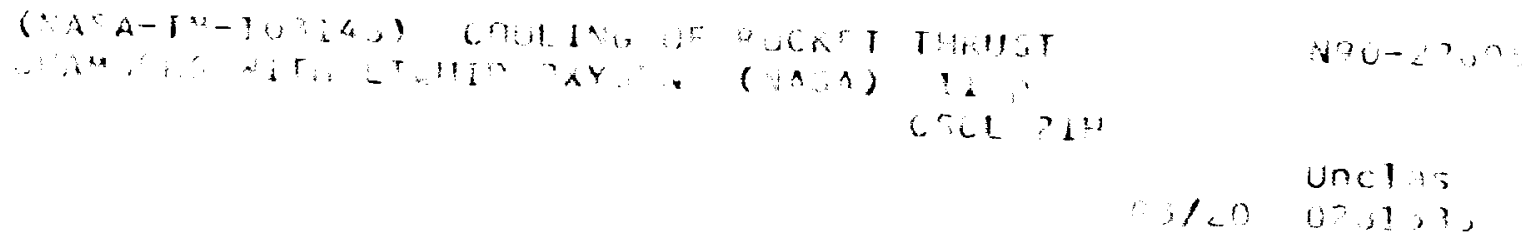

Prepared for the 26th Joint Propulsion Conference cosponsored by the AIAA, SAE, ASME, and ASEE Orlando, Florida, July 16-18, 1990 



\author{
Elizabeth S. Armstrong and Julie A. Schlumberger \\ National Aeronautics and Space Administration \\ Lew is Research Center \\ Cleveland, Ohio $4+135$
}

\section{Abstract}

Rocket engines using high pressure liquid oxygen (LOX) and kerosene ( $R P_{-1}$ ) as the propellants have been considered for future launch vehicle propulsion. Cenerally, in regeneratively cooled engines. the fuel is used to cool the combustion chamber. However, hydrocarbons such as RP-1 are limited in their cooling capability at high temperatures and pressures. Therefore, Lox is being considered as an alternative coolant. However, there has been concern as to the effect on the integrity of the chamber liner if oxygen leaks into the combustion zone through fat igue cracks that may develop between the cooling passages and the hot-gas side wall. To address this concern, an investigation was previously conducted with simulated fatigue cracks upstream of the thrust ${ }^{2}$ chamber throat. When these chambers were tested, an unexpected melting in the throat region developed which was not in line with the simulated fatigue cracks.

The current experimental program was conducted in order to determine the cause for the failure in the earlier thrust chambers and to further investigate the effects of cracks in the thrust chamber liner upstream of the throat. The thrust chambers were tested at oxygen-to-fuel mixture ratios from 1.5 to 2.86 at a nominal chamber pressure of $8.6 \mathrm{MPa}$. As a result of the test series, the reason for the failure occurring in the earlier work was determined to be injector anomalies. The LOX leaking through the simulated fatigue cracks did not affect the integrity of the chambers.

\section{Int roduction}

Preliminary design studies ${ }^{1}$ for future space transportation systems have shown a benefit for high pressure booster engines using liquid oxygen (LOX) and a hydrocarbon fuel as the propellants. The candidate hydrocarbon fuels for future launch systems were kerosene (RP-1), propane, and methane. When cooling a high pressure rocket engine thrust chamber, the fuel is typically used to regeneratively cool the thrust chamber. However, at high pressures and temperatures, hydrocarbon fuels can decompose in the cooling passages causing coke to build up on the heat transfer surface and trace amounts of sulfur-containing compounds can cause corrosion of the copper wall. Because of the limitations of hydrocarbon regenerative cooling, liquid oxygen is being considered as an alternative coolant. There are two concerns with Lox as a coolant: heat transfer capability; and the effect of leakage into the combustion zone if cracks should develop in the chamber liner.

Analyses 1,2 has shown that liquid oxygen can cool rocket engines at chamber pressures up to $27.6 \mathrm{MPa}$ (4000 psia) and experimental work ${ }^{3-6}$ has demonstrated liquid oxygen cooling up to $13.8 \mathrm{MPa}$ (2000 psia) and still maintain reasonable pressure drops. In previous experimental work ${ }^{4}$ fatigue cracks developed in the throat region, similar to

Copyright $\quad 1990$ by the American Institute of Aeronatic and Astronautics, Ins. No copyright is asserted in the United States under Title 17. U.S. Code. The U.S. Government has a royalty-free license to exercise all rights under the copyright claimed herein for Governmental purposes. those which develop with fuel cooling, at chamber pressures of $4.1 \mathrm{MPa}(600 \mathrm{psia})$ and $8.6 \mathrm{MPa}$ (1250 psia) and the leaking LOX coolant had no effect on the chamber wall. In the more recent experimental work, 5 the effect of oxygen leaking into the combustion zone through machined slots (simulating fatigue cracks) upstream of the throat was evaluated. The results of the testing showed that the leaking Lox did not have a deleterious effect on the chamber performance and there was no evidence of chamber wall ignition. However, there was unexplained melting in the throat region of the thrust chambers. A number of theories were postulated as to the cause of the melting. The two most viable theories were: (1) that as a result of injector anomalies, which produced an oxygen-rich zone along the chamber wall beginning at the injector face and continuing past the throat, melting occurred at the chamber throat; and (2) that the melting could be a result of oxygen leaking into the chamber through simulated cracks upstream of the throat, and the oxygen may have reacted with the chamber wall or with the unburned $\mathrm{RP}_{-1}$ near the chamber wall, resulting in the melting.

The objectives of this program were to acquice more data on the feasibility of LOX cooling and to substantiate one or both of these theo$r i$ es through more testing, as recommended in the previous analysis. ${ }^{5}$ The progran covered three configurations, as shown in Table I. First, a thrust chamber without simulated fatigue cracks was tested using the same injector that was used in the previous program. Second, the thrust chamber without simulated cracks was tested with a new injector that does not cause oxygen-rich zones on the chamber walls. Third, the new injector was tested using a similar thrust chamber with LOX leaking through simulated cracks upstream of the throat. These LOX-cooled thrust chambers were tested at a nominal chamber pressure of $8.6 \mathrm{MPa}$ (1250 psia) over a range of oxygen-to-fuel ratios from 1.50 to 2.86 , approximately the same operating conditions as the previous program. 5

\section{Apparatus}

The hardware used for this program consisted of two 61-element injectors, a resonator, and two combustion chambers. Figure 1 shows the dimensions of the hardware. The injector face diameter is $12.2 \mathrm{~cm}(4.8 \mathrm{in}$.) as is the diameter of the cylindrical section. At the throat section, the diameter is $6.6 \mathrm{~cm}(2.6 \mathrm{in}$.) while the diameter at the nozzle exit is $15.9 \mathrm{~cm}(6.26$ in.), for an exit area ratio of 5.8 . The length from the injector face to the throat is $39.37 \mathrm{~cm}(15.5 \mathrm{in}$.) and the distance from the throat to the exit plane is $17.78 \mathrm{~cm}(7.00 \mathrm{in.})$.

\section{Injector and Resonator}

Figure 2 shows a 61-element triplet injector with 4 radial rings of elements and a central quad 
element that provided 3 oxidizer streams impinging on a straight fuel stream. The three innermost radial rings were arranged in an oxidizer-fueloxidizer $(0-F-0)$ sequence to provide good propellant mixing, fuel vaporization, and mass flux distribution. The outermost radial ring consisted of F-0 doublet showerheads to provide more fuel in the outer zone, which resulted in film cooling of the chamber wall. The first injector, injector 288, used in this program was originally fabricated with 61 elements as triplets arranged in a pattern to provide LOX tangential fans. Because this pattern had resulted in high temperatures at the chamber wall,t the injector was modified in the outer ring of elements by welding all the holes to close them and then redrilling as F-0 doublet showerheads. However, the use of this injector in the program reported in Ref. 5 resulted in oxygenrich streaks on the chamber wall. The streaking did not appear to be a function of the mixture ratio, as the streaks occurred at operating conditions above and below the stoichiometric mixture ratio. Subsequently, water-flow tests showed that several of the oxygen element streams did not flow at the proper angle, as well as a number of the fuel element streams. The elements in the outer row of the second injector, injector 309, were drilled as showerheads and water-flow tests indicated that all the oxygen and fuel element streams were properly aligned. Also, the hot fire tests showed that there were no oxygen-rich streaks on the chamber wall.

A water-cooled resonator was used in this investigation to provide stable combustion. It was composed of 16 acoustic cavities arranged evenly around its inside surface. The cavities were in line with the chamber at its edge and were $3.63 \mathrm{~cm}(1.43 \mathrm{in.})$ long. The injector formed the inner wall of the cavities which was $2.54 \mathrm{~cm}$ (1.0 in.) long. This corresponded to a quarter wave tube to dampen the serond tangential frequency of 9700 cycles/sec wich was the expected frequency of the combustion oscillations that would cause instability. A hydrogen-oxygen spark torch igniter was located in the resonator wall just downstream of the acoustic cavities.

\section{Combustion Chamber}

Figure 1 shows the dimensions of the combus tion chambers used in this test program. The two thrust chamber liners were fabricated from oxygenfree, high conductivity (OFHC) copper and contained 100 axial milled channels for the coolant passages. Electroformed nickel was used as the closeout material. To determine the effects of cracks occurring upstream of the throat, chamber 704 was fabricated with two machined slots $180^{\circ}$ apart. The machined slots were $0.4 \mathrm{~cm}(0.16 \mathrm{in.})$ long and $0.0127 \mathrm{~cm}(0.005 \mathrm{in}$.) wide. Figure 3 shows one of the slots in chamber 704 after the chamber had been fired. From the continuity equation and assuming constant density across the slots, the leakage through each slot is calculated to be approximately 25 percent of the coolant through a given cooling passage, or an estimated 0.25 percent of the total coolant flow. On chamber 704 , the machined slots were located $12.7 \mathrm{~cm}$ ( 5.0 in.) downstream of the injector face. Due to the coolant manifold and the resonator, this was the closest location to the injector that slots could safely be machined into the chamber liner. Chamber 705 was fabricated without the slots.
The LOX in the coolant passages used a separate feed system from the Lox flowing through the injector. The LOX coolant was countercurrent to the combustion gases and flowed at approximately the same flowrate as the lox used for combustion.

\section{Instrumentation}

The test facility and hardware were thoroughly instrumented to measure the performance and heat transfer paraneters of the thrust chambers. All of the critical instrumentation was duplicated for more accurate measurement of the parameters. The Lox flow rate for combustion was measured by two turbine floweters as was the LoX flow rate for the conlant. The RP-1 propellant flow rate was measured by two venturi meters. The pressures were measured by strain-gauge, bridge-type pressure transducers, both fre absolute and differential measurements. Sea level thrust was measured by one load cell with two bridges.

Temperature neasurements were determined by either Platinum Resistant Thermometers (PRTs). for temperatures below $110 \mathrm{~K}\left(200^{\circ} \mathrm{R}\right)$, or ChromelConstantan $(\mathrm{Cr} / \mathrm{C})$ thermocouples, for all temperatures above $110 \mathrm{~K}\left(200^{\circ} \mathrm{R}\right)$. The thrust chambers were instrumented with $\mathrm{Cr} / \mathrm{C}$ thermocouples imbedded in the $r i b$ between the coolant channels approximately $1.17 \mathrm{~mm}(0.0) 16 \mathrm{in.})$ from the hot-gas wall Both chambers had 20 thermocouples evenly spaced at 4 circumferential locations in 5 axial positions. Figure $\&$ shows the axial thermocouple locations for both chambers as well as the axial slot location for rhamber 704 .

During each test, data were recorded using a transient data acquisition and recording system that records data every $0.02 \mathrm{sec}$ and averages the data over 5 recordings, with the average reported every $0.1 \mathrm{sec}$. The data is then transferred to a centrally located mainframe computer so that it can be easily accessed in real time.

\section{IEST PROCEULRE}

The combustion chambers were tested at a nominal chamber pressure of $8.6 \mathrm{MPa}(1250 \mathrm{psia})$ and over a mixture ratio $(0 / F)$ range of 1.50 to 2.86 . Table 1 gives the hardware configurations and Table II gives the test conditions for the test series. All the valve sequencing necessary for a repeatable test cycle was programmed into a solidstate timer that is repeatable to within $\pm 0.001 \mathrm{sec}$. Fuel and oxidizer flows were controlled by fixedposition valves and propellant tank pressure. The valve settings arcuracy allowed the chamber pres sure to be repeatable only to $\pm 240 \mathrm{KPa}( \pm 35 \mathrm{psi})$. For most of the runs, the target chamber pressure was 8.63 MPa (1250 psia). However, for several runs, other pressures were targeted in an effort to repeat data from the previous test programs described in Refs. I and 5. Coolant inlet pressure was nominally $15.0 \mathrm{MPa}(2200 \mathrm{psia})$ and was controlled by conlant tank pressure. Coolant exit pressure was kept constant above critical pressure $(5.08 \mathrm{MPa})$ by a closed-loop controller positioning a back pressure valve. The coolant was kept above critical pressure throughout the coolant passages so that two-phase flow did not result in the coolant passages. With this arrangement, the coolant flow rate started high and decreased to the desired value as the steady state condition was reached. 


\section{RESULTS AND DISCUSSION}

Two thrust chambers were tested during this program using three configurations, as shown in Table I. The conditions for these tests are shown in Table II. Each conf iguration is described below.

Eight complete runs were conducted with configuration 1, chamber 705 and injector 288. After the first eight complete runs, number 58-66, the chamber was inspected and small fatigue cracks were detected at the throat. The fatigue cracks were in line with the oxygen-rich streaks that were a result of injector anomalies.

Conf iguration 2, chamber 705 and injector 309, was successfully fired 3 times, runs 87,90 , and 91 . No streaking was detected with the new injector and the fatigue cracks at the throat did not appear to grow in size.

Configuration 3 , with chamber 704 and injector 309 , was fired more than 20 times, with 16 complete runs. The chamber was inspected periodically during testing and there were no signs of damage to the chamber liner, as shown in Fig. 5. There were no signs of increased wall temperature directly upstream of the slots as a result of less LOX in the slotted cooling channels.

During the testing, the chamber walls never reached the metal ignition temperature and there was no deleterious effect on the chamber integrity as a result of the LOX leaking into the combustion zone. Chamber 704, which had slots close to the injector, showed no signs of fatigue cracks or damage of any kind after more than $20 \mathrm{fi}$ ings. Chamber 705, without slots, had fatigue cracks after less than 8 firings when using injector 288 , the injector used previously in Refs, 4 and 5 .

The effect of the injector oxygen-rich streaking far outweighs the possible effects of the Lox leakage through the machined slots. The direction of flow out of the cracks is perpendicular to the main combustion stream so the Lox would tend to get dispersed. Since it is unlikely to reach the opposite side of the chamber, the stream from the slots would only damage the chamber wall near the slots. However, there was no damage near the slots and no significant temperature rise. The direction of flow from the injector elements is relatively parallel to the main combustion stream, even for misaligned injector elements, and, therefore, the oxygen stream is less likely to be dispersed. A misaligned injector element could easily impinge on the chamber wall, causing streaking. Approximately one percent of the injected oxygen flows through each hole. If 3 or 4 holes are misaligned, 3 or 4 percent of the total oxygen would be impinging on the chamber wall, as compared to 0.25 percent of the oxygen coolant leaking through one of the machined slots. These results would indicate that the melting in the previous test series was due to the injector and not the oxygen leaking into the chamber from the cooling channels.

The tests were conducted safely wi thout any damage to the facility or attached hardware. Therefore, it is concluded that LOX can be used safely as a coolant, even if cracks should develop in the chamber wall upstream of the throat.

\section{Chamber Perfornance}

Figure 6 shows the $C^{*}$ efficiency (characteristic exhaust velocity efficiency) as a function of the mixture ratio for chamber 705. The uncertainty in the $C^{*}$ efficiency is $\pm 1,47$ percent and the uncertainty in the mixture ratio is \pm 2.12 percent, as calculated using the uncertainty methodology described in Ref. 7. The $\mathrm{C}^{*}$ efficiency is the experimental $C^{*}$ divided by the theoretical $\mathrm{C}^{*}$, where the theoretical $\mathrm{C}^{*}$ is calculated from the CEC computer program for the given combustion conditions. The experimental $C^{*}$ is calculated from

$$
C^{*}=\frac{P c * t t * G_{e}}{\dot{m}_{\text {total }}}
$$

where $P C$ is the chamber pressure, $A t$ is the throat area, $G_{e}$ is the Earth's gravitational constant, and motal is the total propellant mass flow. The 0.5 percent increase in Lox flow due to the simulated cracks was too small to affect the performance of the chamber and was not included in these calculations. Except for a few anmialies, the $C^{*}$ efficiency was above 92 percent, which is acceptable performance for this injector conf iguration.

\section{Chamber Wall Temperature}

Thermocouples were located on the chambers at the slot locations and $2.54 \mathrm{~cm}(1.0 \mathrm{in}$.) downstream of the slots to determine the effect of LOX leaks on wall temperature. The uncertainty in the thermocouple readings was $=1.0$ percent. A onedimensional analysis was used to determine the hot-gas side wall temperatures from the thermocouple readings.

In Fig. 7, the wall temperatures downstream of the slots in chamber $704(15.2+\mathrm{cm}$ downstream from the injector) are conpared for the three configurations. The two peak temperatures in Fig. 7 indicate a hot spot on the chamber wall. The wall temperatures at the slots are well within the data scatter of the wall temperatures where there were no slots. This would indicate that the leaking oxygen did not have any measurable effect on the wall temperature dicectly downstream of the machined slots. There did not appear to be any appreciable film cooling, any hot spots due to reaction of the excess oxygen with the wall, or any hot spots due to combustion of the excess oxygen with unburned fuel next to the wall.

Hot-gas side wall temperatures at the throat are compared in Fig. 8 for the three configurations. The wall temperatures at the throat show a wider scatter than those upstream of the throat. Also, the temperatures appear to rise slightly with increasing mixture ratio, which would be expected since the combustion temperature rises with the mixture ratio. There is no significant change in wall temperature between the slotted chamber (704) and the unslotted chamber (705).

\section{SLMMARY OF RESLILTS}

Two OFHC copper thrust chambers with identical chamber geometry were tested with LOX and $\mathrm{RP}_{-1}$ as propellants and liquid oxygen (LOX) as the coolant at a nominal chamber pressure of $8.6 \mathrm{MPa}$ 
(1250 psia) over a mixture ratio (0/F) range of 1.5 to 2.86 . To determine the cause of the melting of the chambers in the previous lest series, the two theories were evaluated through experimental data acquired in this program. These two theories were: (1) that the melting could be a result of injector streaking. which began at the injector face and continued past the throat: and (2) that the melting could be a result of oxygen leaking through the simulated cracks into the chamber, and the oxygen may have reacted with the chamber wall or with the unburned RP-1 near the chamber wall. A similar chamber to those tested previously, but without simulated cracks, was fired using the old injector, and fatigue cracks developed after less than five firings. A similar chamber with simulated cracks close to the injec tor face was fired using a new injector that did not produce oxygen-rich streaks and no fatigue. cracks or damage of any kind resulted. Hence, it was determined that the injector anomalies caused the previous melting, not the leaking oxygen. Also, oxygen can cool the chamber sufficiently even if cracks develop upstream of the throat. follows:

0 ther results from this test series are as

1. Lox leaking into the combustion zone through simulated fatigue cracks (machined slots) did not have a deleterious effect on the chambers, i.e.. there was no evidence of melting or of the wall reaching the metal ignition temperature.

2. Wall temperature measurements from the chamber with simulated fatigue cracks were within the data scatter of the wall temperature measurements from the chamber without simulated fatigue cracks, indicating that there was no appreciable film cooling, no hot spots due to reaction of the excess oxygen with the wall, and no hot spots due to combustion of the excess oxygen with unburned fuel next to the wall.

3. The effects of injector oxygen rich streaking can far outweigh the effects of lox leaking through simulated fatigue cracks because of the magnitude and direction of the oxygen flow.
4. The results of these tests indicate that LOX can be used safely as a coolant, even if some cracks should develop in the chamber wall upstream of the throat.

\section{REFERENCES}

1. Luscher, H.P., and Mellish, J.A., "Advanced High Pressure Engine Study for Mixed-Mode Vehicle Applications," NASA CR-135141, 1977.

2. Rousar, D.C., and Miller, F., "Cooling with Supercritical 0xygen," AIAA Paper 75-1248. Sept. 1975

3. Price. H.G.. "Cooling of High-Pressure Rocket Thrust Chambers with Liquid Oxygen." Lournal of Spacecraft and Rackets, Vol. 18, No.4, July-Aug. 1981, pp. 338-343.

4. Price, H.G., and Masters, P.A., "Liquid Oxygen Cooling of High Pressure LOX/Hydrocarbon Rocket Thrust Chambers," NASA TM-88805, 1986.

5. Armstrong, E.S., "Liquid 0xygen Cooling of Hydrocarbon Fueled Rocket Thrust Chambers." AlAA-89-2739, July 1989.

6. Dederra, H, and Kirner, E., "High Pressure Rocket Engine Liquid Oxygen Technology," Presented at the XXXVII Congress of the Interna-tional Astronautical Federation, IAF Paper $76-174.0 \mathrm{ct} .1976$.

7. Ahernethy, R.B.. Colbert, D.L., and Powell, B.D. ICRPG Handbook for Estimating the Uncertainty in Medsurements Made with Liquid Propel lant Rocket Engine Systems. JANNAF Performance Standardization Working Group Report. CPIA No. $180,1969$.

8. Gordon, S., and McBride, B.J., Computer Program for Calculation of Complex Equilibrium Compusitions, Rocket Performance, Incident and Reflected Shocks, and Chapman-Jouguet Detonations. NASA SP-273, 1976.

TABLE [ . - HARDHARE. CONFIGURATIONS

\begin{tabular}{|c|c|c|c|c|}
\hline $\begin{array}{c}\text { Config- } \\
\text { uration }\end{array}$ & $\begin{array}{c}\text { Injector } \\
\text { serial } \\
\text { number }\end{array}$ & $\begin{array}{c}\text { Chamber } \\
\text { serial } \\
\text { number }\end{array}$ & $\begin{array}{c}\text { Slot location, } \\
\text { co from } \\
\text { injector }\end{array}$ & $\begin{array}{c}\text { vumber of } \\
\text { complete } \\
\text { runs }\end{array}$ \\
\hline 1 & 288 & 705 & No slots & 8 \\
2 & 309 & 705 & No slots & 3 \\
3 & 309 & 704 & 8.89 & 16 \\
\hline
\end{tabular}


TABLE II. - TEST CONDITIONS

\begin{tabular}{|c|c|c|c|c|c|c|c|c|c|c|c|}
\hline \multirow[t]{2}{*}{ Run } & \multirow{2}{*}{$\begin{array}{l}\text { Config- } \\
\text { uration }\end{array}$} & \multicolumn{2}{|c|}{ Chamber pressure } & \multirow[t]{2}{*}{$0 / F$} & \multicolumn{2}{|c|}{ Coolant flowrate } & \multicolumn{2}{|c|}{ Oxidant flowrate } & \multirow{2}{*}{$\begin{array}{l}\text { Vacuum, } \\
\text { kN }\end{array}$} & \multirow{2}{*}{$\begin{array}{c}\text { Thrust, } \\
\text { lbf }\end{array}$} & \multirow{2}{*}{$\begin{array}{c}\text { Character- } \\
\text { istic } \\
\text { exhaust } \\
\text { velocity, } \\
\text { efficiency, } \\
\text { c }^{*}\end{array}$} \\
\hline & & $\mathrm{MPa}$ abs & psia & & $\mathrm{kg} / \mathrm{sec}$ & $\mathrm{lbm} / \mathrm{sec}$ & $\mathrm{kg} / \mathrm{sec}$ & $1 \mathrm{bm} / \mathrm{sec}$ & & & \\
\hline \begin{tabular}{|r}
58 \\
59 \\
60 \\
61 \\
62 \\
63 \\
65 \\
66 \\
75 \\
76 \\
79 \\
81 \\
82 \\
87 \\
90 \\
91 \\
92 \\
93 \\
94 \\
95 \\
98 \\
99 \\
102 \\
103 \\
104 \\
105 \\
106
\end{tabular} & $\begin{array}{l}\downarrow \\
2 \\
2 \\
2 \\
3\end{array}$ & $\begin{array}{l}8.15 \\
8.54 \\
8.66 \\
9.01 \\
8.89 \\
8.62 \\
8.37 \\
8.36 \\
8.26 \\
8.91 \\
8.09 \\
8.56 \\
8.61 \\
8.22 \\
9.14 \\
9.16 \\
8.76 \\
8.78 \\
8.69 \\
8.32 \\
8.27 \\
8.36 \\
8.62 \\
8.61 \\
8.61 \\
8.55 \\
8.57\end{array}$ & $\begin{array}{l}1182 \\
1239 \\
1256 \\
1307 \\
1290 \\
1250 \\
1214 \\
1213 \\
1198 \\
1292 \\
1173 \\
1242 \\
1249 \\
1193 \\
1326 \\
1329 \\
1271 \\
1274 \\
1261 \\
1207 \\
1200 \\
1212 \\
1251 \\
1249 \\
1249 \\
1240 \\
1243\end{array}$ & $\begin{array}{l}1.58 \\
1.76 \\
1.76 \\
2.20 \\
2.18 \\
2.05 \\
1.94 \\
1.91 \\
1.91 \\
1.83 \\
1.75 \\
2.00 \\
2.03 \\
1.92 \\
2.45 \\
2.75 \\
1.97 \\
2.16 \\
2.28 \\
2.63 \\
2.14 \\
2.86 \\
1.92 \\
2.08 \\
2.28 \\
2.47 \\
2.35\end{array}$ & $\begin{array}{l}14.90 \\
14.80 \\
14.70 \\
13.60 \\
13.50 \\
13.80 \\
14.10 \\
13.70 \\
14.60 \\
14.90 \\
14.40 \\
14.30 \\
14.50 \\
14.50 \\
14.30 \\
14.50 \\
14.40 \\
14.30 \\
13.40 \\
14.10 \\
14.50 \\
14.30 \\
12.90 \\
11.80 \\
12.00 \\
12.30 \\
12.00\end{array}$ & $\begin{array}{l}32.70 \\
32.50 \\
32.30 \\
29.90 \\
29.60 \\
30.30 \\
31.00 \\
30.10 \\
32.10 \\
32.80 \\
31.60 \\
31.50 \\
31.80 \\
31.80 \\
31.40 \\
32.00 \\
31.60 \\
31.40 \\
29.50 \\
31.00 \\
31.80 \\
31.50 \\
28.30 \\
25.90 \\
26.40 \\
27.00 \\
26.40\end{array}$ & $\begin{array}{l}11.40 \\
10.70 \\
10.90 \\
12.10 \\
12.00 \\
11.50 \\
11.00 \\
11.10 \\
11.70 \\
11.70 \\
11.90 \\
12.50 \\
12.50 \\
12.50 \\
13.30 \\
13.70 \\
11.80 \\
13.10 \\
12.30 \\
12.40 \\
11.50 \\
12.90 \\
11.40 \\
11.80 \\
12.10 \\
12.40 \\
12.20\end{array}$ & $\begin{array}{l}25.10 \\
23.60 \\
23.90 \\
26.70 \\
26.40 \\
25.20 \\
24.10 \\
24.50 \\
25.80 \\
25.70 \\
26.10 \\
27.60 \\
27.50 \\
27.40 \\
29.20 \\
30.20 \\
25.90 \\
26.70 \\
27.00 \\
27.20 \\
25.40 \\
28.30 \\
25.00 \\
25.90 \\
26.60 \\
27.20 \\
26.80\end{array}$ & $\begin{array}{l}37.56 \\
39.62 \\
40.03 \\
42.44 \\
41.57 \\
39.98 \\
38.35 \\
38.32 \\
42.51 \\
43.25 \\
38.77 \\
41.04 \\
41.49 \\
40.62 \\
45.47 \\
45.83 \\
45.40 \\
45.87 \\
45.34 \\
43.56 \\
42.76 \\
43.26 \\
44.22 \\
44.31 \\
44.31 \\
44.04 \\
44.29\end{array}$ & $\begin{array}{rr}8 & 445 \\
8 & 907 \\
9 & 000 \\
9 & 542 \\
9 & 345 \\
8 & 988 \\
8 & 621 \\
8 & 615 \\
9 & 556 \\
9 & 724 \\
8 & 715 \\
9 & 227 \\
9 & 327 \\
9 & 131 \\
10 & 223 \\
10 & 304 \\
10 & 207 \\
10 & 312 \\
10 & 193 \\
9 & 792 \\
9 & 612 \\
9 & 726 \\
9 & 942 \\
9 & 962 \\
9 & 962 \\
9 & 901 \\
9 & 956\end{array}$ & $\begin{array}{l}89.3 \\
99.8 \\
99.6 \\
96.6 \\
96.1 \\
96 \\
96.8 \\
94.7 \\
88.6 \\
95.4 \\
84.6 \\
86.3 \\
87.3 \\
83.7 \\
92.7 \\
93.7 \\
93.9 \\
93.2 \\
92.6 \\
97.7 \\
91.8 \\
92.3 \\
95.1 \\
93.4 \\
92.9 \\
92.7 \\
92.8\end{array}$ \\
\hline
\end{tabular}



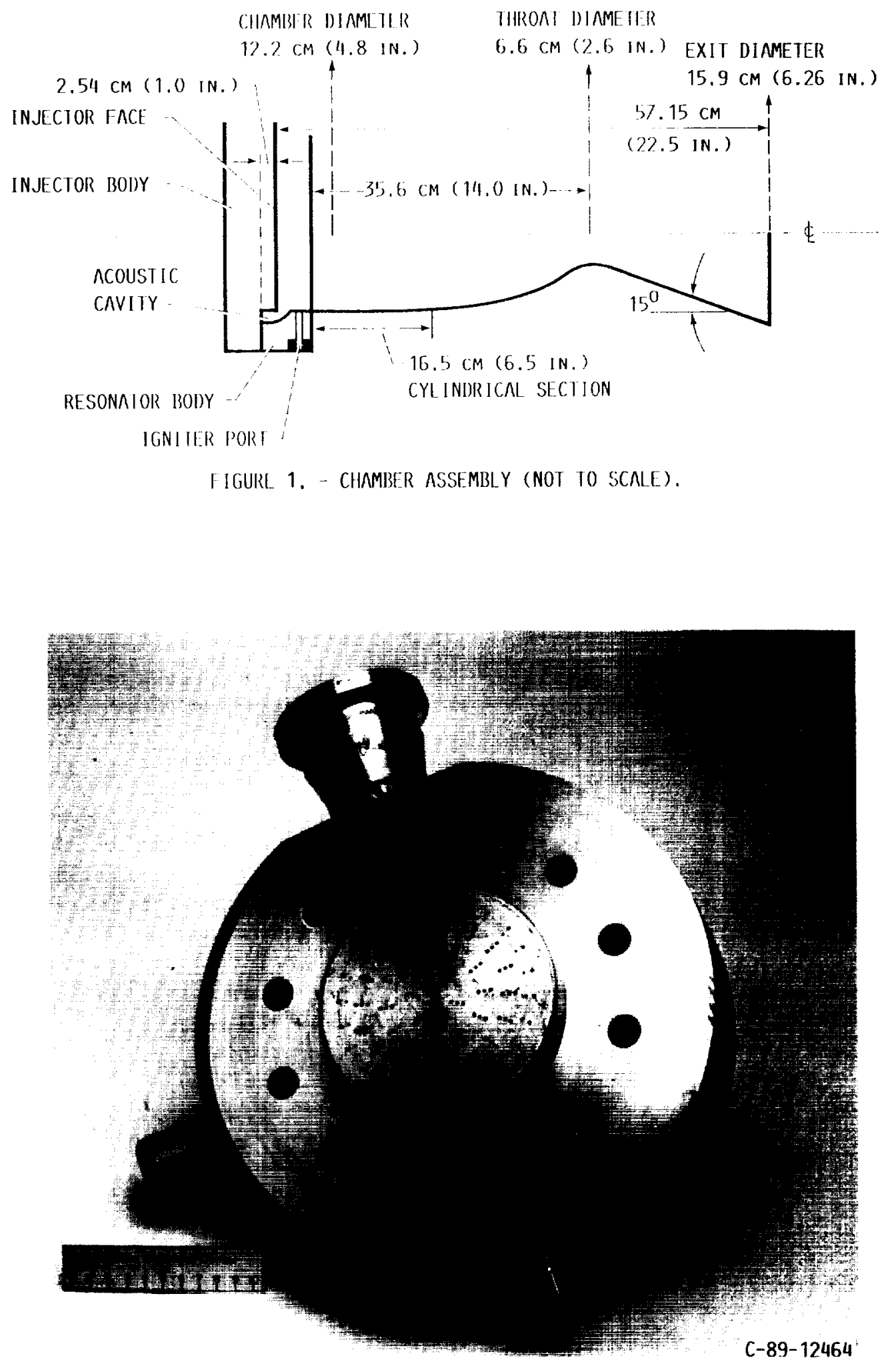

FIGURE 2. - 61 ELEMENT TRIPLET INJECTOR.

ORIGINAL PAGE IS OF POOR QUALITY 


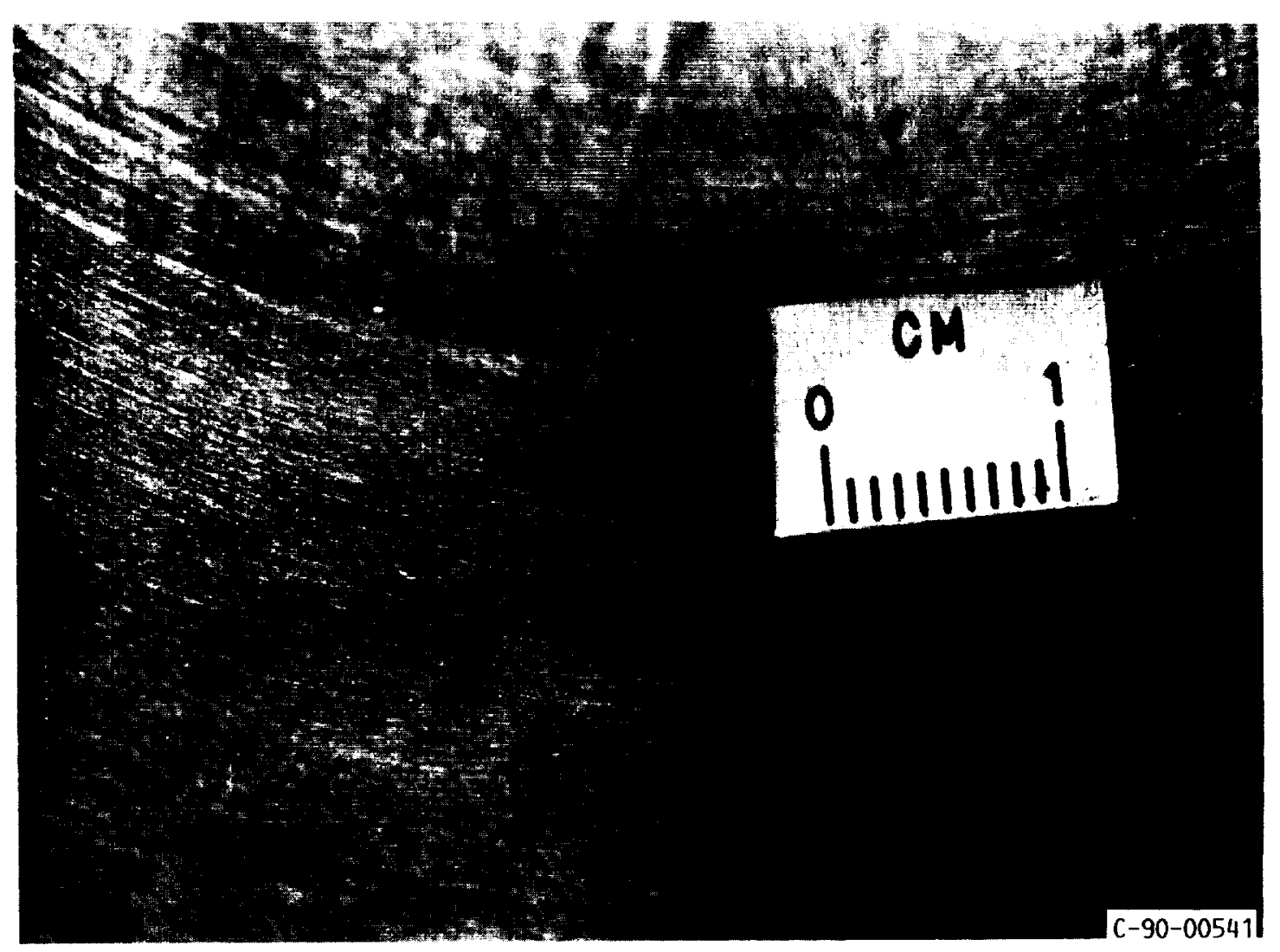

FIGURE 3. - MACHINED SLOT ON CHAMBER 704 AFTER TESTING.

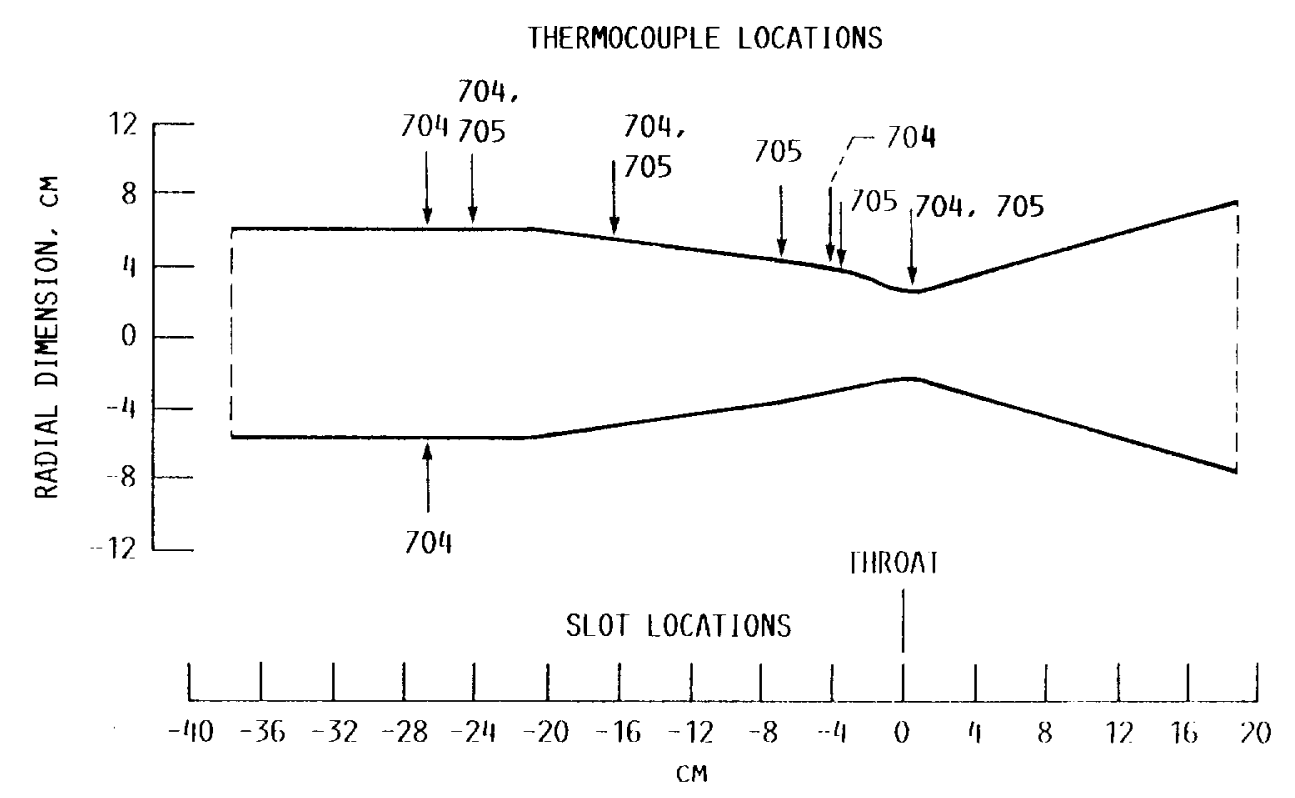

FIGURE 4. - SLOT AND THERMOCOUPLE LOCATIONS. CHAMBER NUMBER INDICATES WHICH CHAMBER HAD THERMOCOUPLES OR SLOTS AT THE GIVEN LOCATION. 


\section{ORIGINAL PAGE \\ BLACK AND WHITE PHOTOGRAPH}

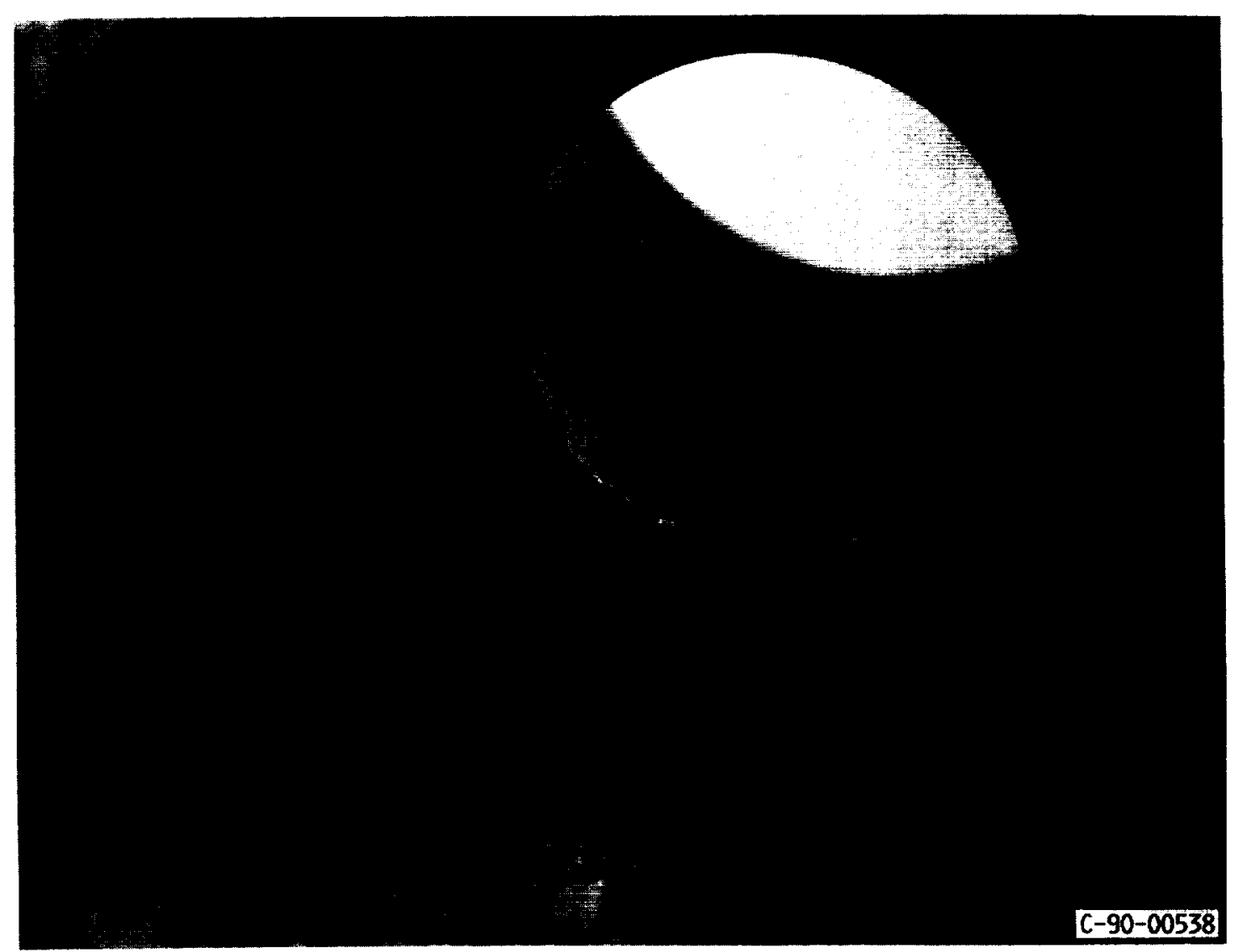

FIGURE 5. - THROAT SECTION OF CHAMBER 704 AFTER 20 FIRINGS. THERE IS NO DAMAGE OF ANY KIND TO THE CHAMBER LINER.

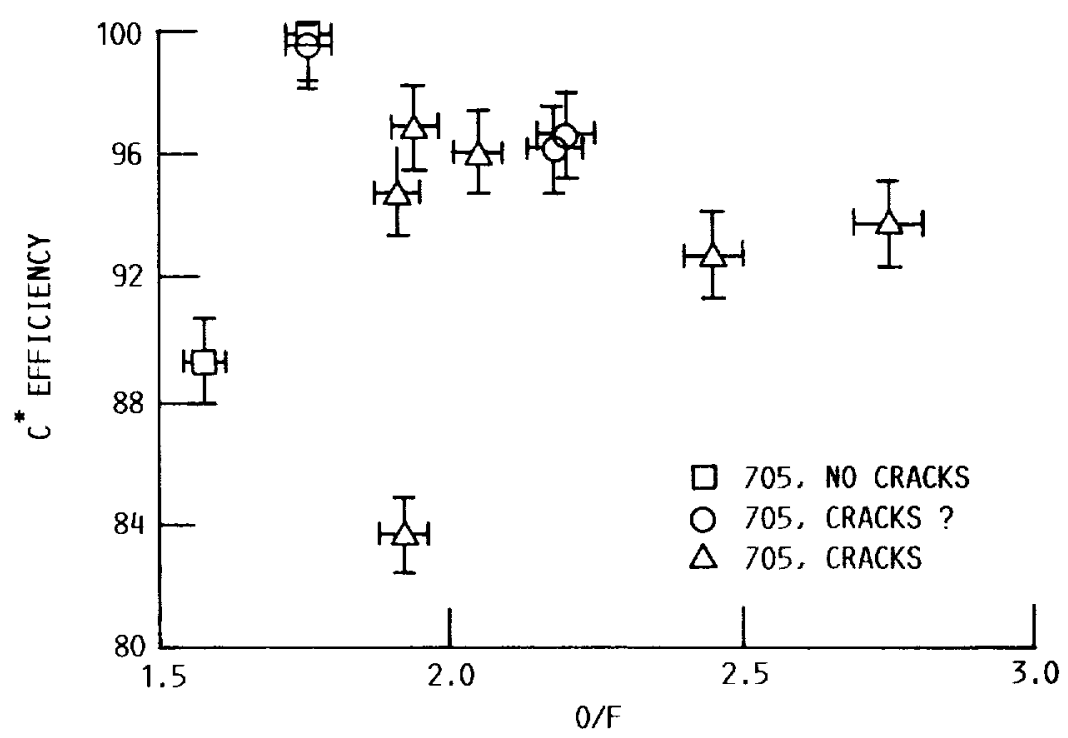

Orinupral Page OF POOR GUALIT:

FIGURE 6. - CHARACTERISTIC EXHAUST VELOCITY EFFICIENCY FOR CHAMBER 705 AS A FUNCTION OF MIXTURE RATIO. THE UNCERTAINTY IN THE DATA IS SHOWN BY THE HORIZONTAL AND VERTICAL BARS FOR EACH POINT. 


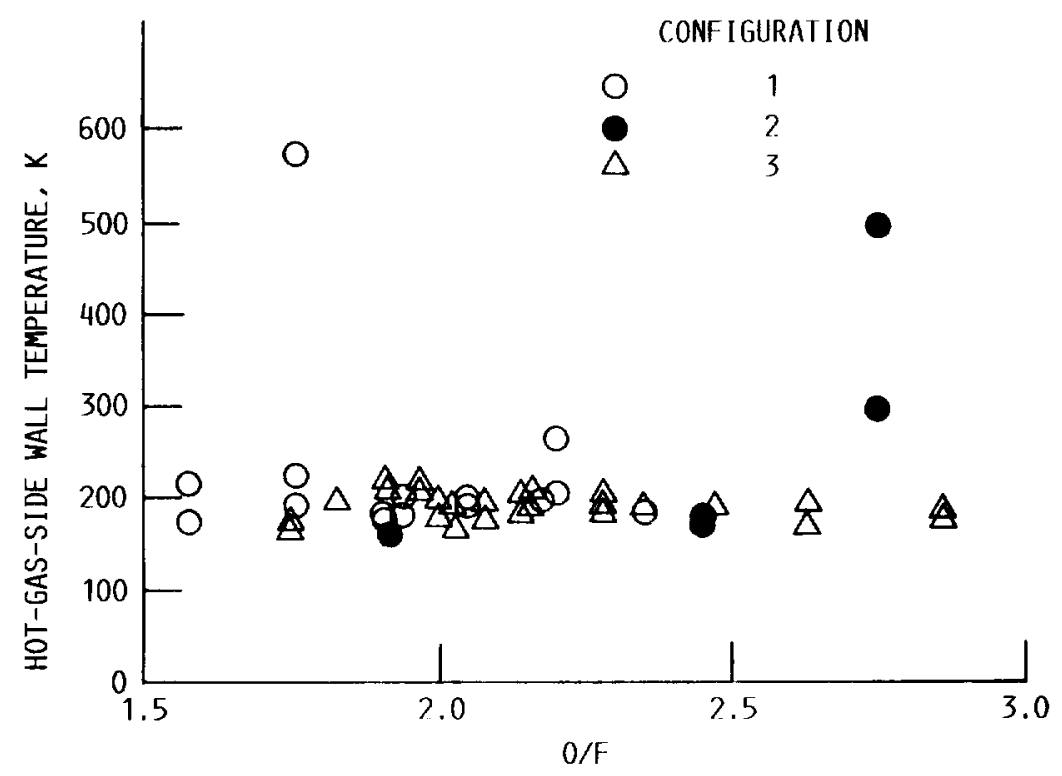

FIGURE 7.- HOT-GAS-SIDE WALL. TEMPERATURES $15.2 \mathrm{cM}$ FROM THE INJECTOR FOR CHAMBERS 704 AND 705.

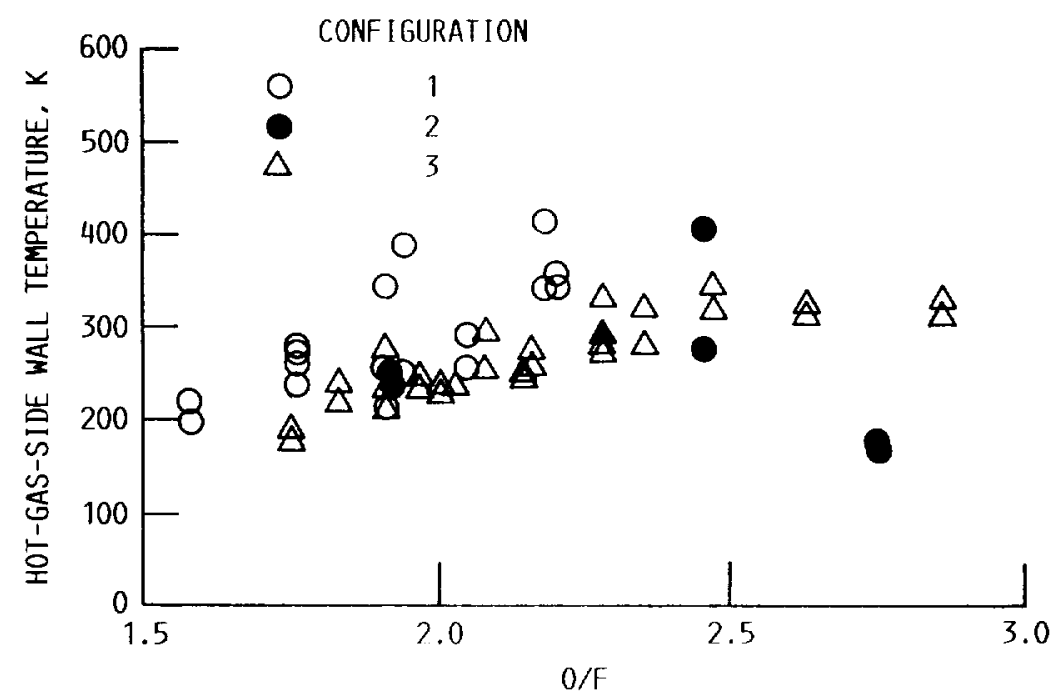

FIGURE 8. - HOT-GAS-SIDE WALI TEMPERATIIRE. AT THE THROAT FOR CHAMBERS 704 AND 705. 


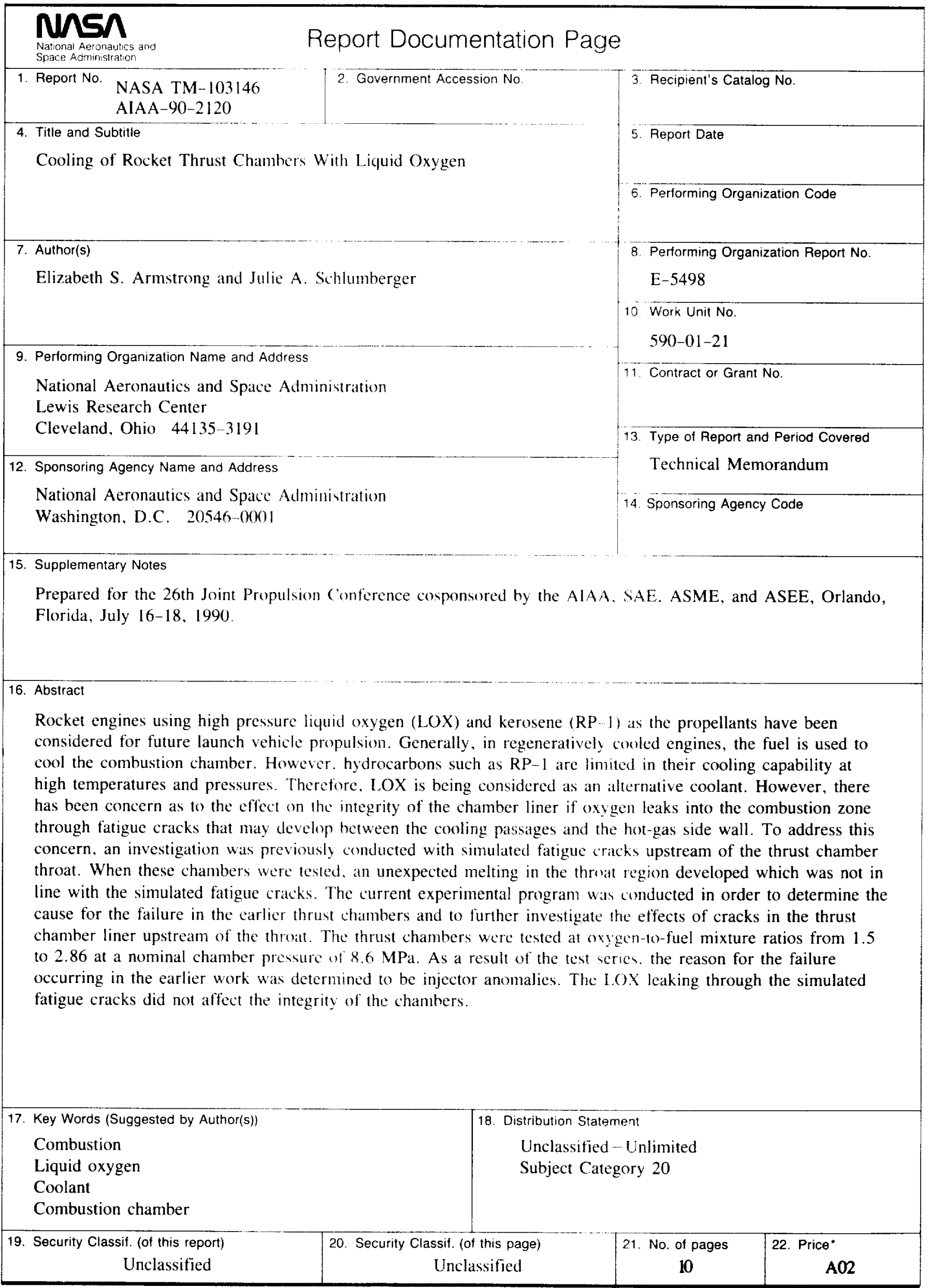

